Illinois State University

ISU ReD: Research and eData

Theses and Dissertations

$7-4-2018$

\title{
The Old Versus The New Equestrian Circus: Demonstrating And Promoting Equine Welfare
}

Veronica Painter

Illinois State University, vapaint@ilstu.edu

Follow this and additional works at: https://ir.library.illinoisstate.edu/etd

Part of the Agriculture Commons, Animal Sciences Commons, Ethics and Political Philosophy Commons, and the Theatre History Commons

\section{Recommended Citation}

Painter, Veronica, "The Old Versus The New Equestrian Circus: Demonstrating And Promoting Equine Welfare" (2018). Theses and Dissertations. 1044.

https://ir.library.illinoisstate.edu/etd/1044

This Thesis is brought to you for free and open access by ISU ReD: Research and eData. It has been accepted for inclusion in Theses and Dissertations by an authorized administrator of ISU ReD: Research and eData. For more information, please contact ISUReD@ilstu.edu. 


\section{THE OLD VERSUS THE NEW EQUESTRIAN CIRCUS: DEMONSTRATING AND PROMOTING EQUINE WELFARE}

\section{VERONICA PAINTER}

\section{Pages}

Circus is an art form that was originally considered as a humanitarian art, promoting equine welfare by shedding a new light on the horse and human relationship. During a time where horses were used for war, work, and transportation; fancy riding and liberty stood as the framework for a new togetherness between man and beast. The animal activist revolution centered on exotic animals in circus, yet the effects of these demanding pressures caused a major blow to the equestrian circus. This comparative study examines possible improvements to the industry in order to keep this art alive. Keeping up with eclectic audiences, improving training tactics and living/working conditions for the performing horse, and engaging in open dialogues with audience members, it is possible to reverse the effects of the dying circus industry. The importance of this study lies in the future and welfare of the working horse. When comparing demands of work, career longevity, and post-career options for working horses, the circus horses' welfare clearly exceeds that of sport horses. With a surplus of jobless and homeless horses combined with increasing numbers sent to slaughter, the equestrian circus serves as a favorable option for the working equine.

KEYWORDS: horse; Astley; equine welfare; animal activism; traditional circus; contemporary circus 


\title{
THE OLD VERSUS THE NEW EQUESTRIAN CIRCUS: DEMONSTRATING AND PROMOTING EQUINE WELFARE
}

\author{
VERONICA PAINTER
}

A Thesis Submitted in Partial Fulfillment of the Requirements for the Degree of

\section{MASTER OF SCIENCE}

School of Theatre and Dance

\section{ILLINOIS STATE UNIVERSITY}


Copyright 2018 Veronica Painter 


\title{
THE OLD VERSUS THE NEW EQUESTRIAN CIRCUS: DEMONSTRATING AND PROMOTING EQUINE WELFARE
}

\author{
VERONICA PAINTER
}

COMMITTEE MEMBERS:

Ann Haugo, Chair

Li Zeng

Paul Dennhardt 


\section{AKNOWLEGMENTS}

Firstly, I would like to thank Professor Ann Haugo for her continuous support of my interests and interdisciplinary studies. Encouraging me to follow my passions into my research has kept me motivated and succeeding within the program. Her patience and motivation is greatly appreciated. There is no way I could have done this specialized work without her.

Next, I would like to thank my committee members Paul Dennhadrt and Li Zeng for their support and flexibility with my project. Combining the arts and sciences is never an easy process. Their support and encouragement has kept me on track and ensured that I am making the right moves for my academic career.

I would like to thank the circus arts of Illinois State University. ISU's diamond in the rough, the Gamma Phi Circus does not get the appreciation it deserves. To find a public school that offers specialized area of both research and practice in the circus is truly something rare and valuable.

And finally, research in the Circus and Allied Arts Collection in the Special Collections of Milner Library first sparked my interest in this area of research. Maureen Brunsdale and Mark Schmitt run such a unique and passionate program, I would not have been able to find my niche in graduate studies.

V.P. 


\section{CONTENTS}

Page

ACKNOWLEDGMENTS

$\begin{array}{ll}\text { CONTENTS } & \text { ii }\end{array}$

INTRODUCTION: THE HISTORY OF PERFORMING HORSES IN THE CIRCUS

AND THE TURN OF AUDIENCE PERCEPTIONS 1

CHAPTER I: ANIMAL ACTIVISM, THE EQUESTRIAN CIRCUS, AND THE

WELFARE OF THE PERFORMING HORSE

CHAPTER II: DIFFERENCES IN PRODUCTION THEMES OF THE OLD

VERSUS THE NEW EQUESTRIAN CIRCUS

CHAPTER III: IMPLEMENTING PROPER TRAINING TECHNIQUES TO

PROMOTE WELFARE

CONCLUSION: THE FUTURE OF THE EQUESTRIAN CIRCUS AND

WELFARE OF THE PERFORMING HORSE

REFERENCES 
INTRODUCTION: THE HISTORY OF PERFORMING HORSES IN THE CIRCUS AND THE TURN OF AUDIENCE PERCEPTIONS

Phillip Astley is known as the "father of modern circus;" however, according to Marius Kwint, author of "The Legitimization of the Circus in Late Georgian England," Astley was not the first trick-rider, nor the first to include other performers such as dancers and acrobats into equestrian routines, and in fact, he did not even invent the ring which was the basic set-up of the modern circus. He was known to follow trends of the new forming industry, but what set him apart from his competitors was his entrepreneurship. Astley set up his very own ring, no longer having to rely on appearance fees when he performed at various pubs, gardens, and venues in London. The traveling ring revolutionized entertainment, making it available to a wide array of audiences. The introduction of the first established circus was large accomplishment for lower genre of theatre and performing arts. As researched by University of Oxford's art historian, Marius Kwint, starting with Astley's establishment of the first modern circus, the circus assisted in theatrical freedom from its long history of repression and censorship (85).

According to circus historian Domonique Jando, Phillip Astley, the son of a cabinet maker and veneer-cutter, gained trick riding expertise while serving in the cavalry of the Seven Years War (1756-1763), rising to the rank of sergeant major in the regiment of the Colonel Elliott's $15^{\text {th }}$ Light Dragoons regiment. There Astley proved himself as a remarkable horse trainer and rider. Considering himself a master of horsemanship, Astley not only performed different specialty acts, but he also worked as a groom and riding instructor. Astley quickly gained inspiration from Jacob Bates of England who had his home base in Germany. Bates performed equestrian stunts all over the world, from Russia during the years of 1764-1765, to 
American during the years of 1772-1773. Bates was not the only performing trick rider of the times, right there in London was also Price, Johnson, Balp, Coningham, Faulkes, and "Old" Sampson of the London pleasure gardens.

In 1768 in London, Astley opened his riding school near the Westminster Bridge, in a field called Halfpenny Hatch near the Waterloo Station. Taking up his talents as a trainer and riding instructor, he taught in his riding hall in the morning and performed his equestrian feats for audiences in the afternoons. During these years, commercial theatre was just on the brink of development. Different acts Astley would perform would include picking up handkerchiefs off the ground while hanging off of the running horse, playing the pipes while standing on two horses, and performing a headstand on the center of the saddle. He performed battled tactics using swordplay, and also trained horses to perform tricks such as lying still as if to play dead. His show was quite successful in its first summer season. He began to include many theatrical elements such as tumblers, dancers, and musicians.

Astley's shows began to have seasonal themes and displays. In July of 1768, his shows undertook a comic finale, acting out an urban legend of the tailor whose horse refused to carry him. As Kim Baston describes in her article, 'New' Hippodrama, or 'Old' Circus?: Legacy and Innovation in Contemporary Equestrian Performance", the horse would chase Astley, in hot pursuit. As previously mentioned, Astley was not the inventor of trick riding, nor was he the first to ride in the ring or introduce other forms of entertainment to the equestrian circle, but his established amphitheater finally legitimized these art forms.

Jando reveals more detail of Astley's career, stating that by 1770, the success of his performances largely surpassed the success of his riding school. Introducing more novelty entertainment acts was the next step in Astley’s performances. He hired acrobats, rope-dancers, 
wire walkers, and jugglers in order to entertain and fill time voids in between his equestrian acts. In fact, his shows introduced a new character which was borrowed from Elizabethan theatre. This character entertained audiences with juggling, burlesque dances, comedic sketches, and even specific equestrian tricks during any time voids in the performance, and thus the circus clown came about. The tactful combination of the wide array street talents revolutionized entertainment industry and therefore the modern circus was born.

Astley's success spread like wildfire and the rest of the world was soon to follow the trend. In 1782, Astley opened yet another circus in Paris, the Amphitheatre Anglois. A closer competitor rose named Charles Hughes who happened to be a former member of Astley's performance company. In the same year of the Paris opening, Hughes opened the Royal Circus and Equestrian Philharmonic Academy in London. Hughes was the first to call his establishment a "circus", creating the element of the advertising of a new form of entertainment. Not too far from Paris and London, another important circus was put on the map over in Scotland in 1786 under George Jones and William Parker. Researcher Kim Baston states in her article, "Transatlantic Journeys: John Bill Ricketts and the Edinburgh Equestrian Circus," that the Edinburg Circus and the Royal Circus played a large role in the creation of the first American circus, all of which centralized their performance on equestrian arts and riding academies (7).

Kwint describes the popularization of the equestrian circus as a humanitarian movement. Early riding masters now promoted effective and rational horse training techniques with a new enlightened understanding of animals. The equestrian circus offered to prevent savage-like behavior that left animals liable to punishment; however, not everyone was convinced that this was a true stance. An article in the 1785 Morning Herald read, "the encrase of learned animals of the brute species, as horses, dogs, pigs, etc., must touch the feelings of every humane heart, when 
it is known that the tricks they perform are taught by the most excruciating torture" according to Dominique Jando, author of "Short History of the Circus". Though circuses were not majorly singled out until the nineteenth century, the rejection of the equestrian circus started as a small flame that became a wildfire after World War I, an era that Jando calls, "The End of the Equestrian Circus”.

Astley promoted kindness in training and in work with horses. He stated that "mad men and horses will never agree.” After many horse breaking and training manuals and 1796 presentation at the University of Oxford on his scientific training tactics, Astley still ran into legal trouble and criticism on equine welfare. This foreshadowing lead us to the animal activism revolution of the 1970's, and continues on in modern culture. Today it is difficult to find traditional equestrian circuses. On the verge of extinction, a new type of equestrian circus developed and its popularity among general audiences has spread like wildfire. Avoiding such terms like "circus", the new hippodrama is traditional equestrian circus wrapped in a new theme of natural horsemanship. Popular and new equestrian acrobatic shows such as Cavalia are putting a contemporary twist on Astley's original success.

Though the equestrian circus is slowly but surely coming around, shows are still disappearing before more are popping up. While Cavalia's success can be credited to their eclectic and earthy theme through targeting progressive and wealthy audiences, an industry competition is not what currently what the success of the horse currently needs. Traditional and modern circuses both provide an environment and job for equine performers that promote equine welfare, and always have. Yes it is true that Astley's traditional equestrian circus is dying, but with no fault of its own. Outside factors such as pressures on exotic animal performances, out of date themes, and lack of education in horse training have all contributed to the downfall of the 
traditional equestrian circus. Through archival research, the aim of this study is to examine the key factors that lead the traditional equestrian circus to its plummeting future and how this can be reversed through the study of target audience perceptions, proper horse training methodology, and audience education and open dialog.

Adapt or die. A common phrase used in an always and ever changing world. Taking one of the oldest forms of performance, adjusting the appearance on the outside, yet keeping the soul of the art, may be how the industry can be saved. Why might this be important? As we will examine, when we compare the physical, emotional, and mental workload on the performing circus horse, we find that demands are much lower than that of the average sport horse. The equestrian sport industry relies on a high level of competition and money, not showmanship and art. Comparing the lifestyle and work demands of a circus horse to a rodeo, race, or competition horse, we find less injury, longer careers, and forever homes. Circus horses have historically been part of the narrative of the act rather than an instrument for work and sport.

Every industry has its demons, and while historically the circus promoted welfare, one can never be sure of what truly goes on behind the scenes. This study will also examine the proper framework for the equine lifestyle and training in a circus that will promote welfare for generations to come. Cleaning up false notions and ensuring proper standards for the performing horse will ultimately be a favorable option for the working horse. With a surplus of "jobless" and "homeless" horses, the circus can truly stand as a safe haven for horses.

This importance for this comparative study lies in the future of the circus tradition. An art that was fully developed around death defying feats of horsemanship has lost its glamor, thrill, and attraction to non-animal acts of the $20^{\text {th }}$ century. In order for a species to survive, the species must be able to adapt to changes in its environment. Horses are one of the oldest domesticated 
species, working alongside human companions for centuries in order to survive. Both species now exist in an ever demanding, growing, and changing world. In order for the art to survive, it must adapt to modern culture and standards, for the sake and wellbeing of its animal performers. What other option does this ancient art form have?

This current study is a historical and comparative look into the different factors contributing to the downfall and rebirth of the equestrian circus. Further potential exists with data collection of audience attendance, income, and equine habits and training conditions. Through an archival examination of the original use of equine acts in the circus, a comparative examination of new and old circus themes and success rates, and comparative study of different training techniques and equine industry standards, this study aims to provide information to accurately promote higher welfare and a successful future for the equestrian circus, also known as the hippodrama. 


\section{CHAPTER I: ANIMAL ACTIVISM, THE EQUESTRIAN CIRCUS, AND THE WELFARE OF THE PERFORMING HORSE}

Horses have been domesticated throughout recorded history. The earliest extant work on horse training is a manual titled On Horsemanship, written in $350 \mathrm{BC}$ by Xenophon, an Athenian war general and master horseman. Today Xenophon is known as the father of modern horsemanship. His techniques lay as the foundation of all modern horse training tactics. Carrying warriors into battle, pulling equipment, supplies, and families through geographical expansion, plowing fields for agriculture; the horse has been adopted to man as a 'working animal'. Today the horse no longer has to work for the means of human survival in modern society. Equestrian sport competitions, trail rides, therapy programs, racing, sleigh rides, and all recreational activities are now the working fashion for the horse. The equestrian circus is mainly built of working families with their privately owned horses in their performance acts. While the controversy of wild animal acts is a separate ethical and political issue, the ethical concerns of lifestyle welfare for the circus horse has an impact on the success of the hippodrama.

According to researchers Peta Tait and Rosemary Farrell, organized protest were far and few between in the early twentieth century. In their article "Protests and Circus Geographies: Exotic Animals with Edgley’s in Australia”, the animal activist movement started in western countries in the 1970s. The authors describe the history of this social crusade (231). Prior to this movement, circuses were not generally targeted due to circus owners' promoted efforts to ensure the public of animal care, feeding, and veterinary regimes while avoiding the issue of off stage space and containment. Animal liberation grew with the 1970 s social liberation movement. Peter Singer, an Australian philosopher and researcher of applied ethics, broke loose his ideas of utilitarianism. In his book written in 1975, Animal Liberation: A New Ethics for our Treatment of 
Animals, Peter Singer popularized the term 'speciesism', describing the exploitive treatment of animals. Others have commented that his book is a catalog of horrors of human tyranny and it was written as a call to action. In 1988, a journalist Mike McEwen noted Singer's opposition to animal exploitation within his review of the Moscow Circus (Singer 76).

This was all just the start of the animal activist movement in the circus industry. In 1976, the Animal Liberation Front joined many different organizations fighting for animal rights and the organization PETA (People for the Ethical Treatment of Animals) was created in 1980. Fighting for animal rights, these groups do not see their cause as socially constructed, but rather a fight about what it is to be properly human. When Elizabeth Lawrence conducted and analyzed interviews in 1988 in the United States, she discovered that many of the participating activists held an anthropomorphic orientation to saving animals, or what Tait and Ferrell describe as romantic alignments to an idea of untouched nature. Nature struck as the main focus of the wild animal argument. In 1983, Tom Regan, a philosopher and activist, advocated for an ethical approach to animal rights on the idea that all subjects should have rights in life. In his books, The Case for Animals Rights and Empty Cage: Facing the Challenge of Animal Rights, Regan informs readers that both lions and tigers roam over 100 square miles and that this is the major fault of circuses and zoos, the limited habitat space and the loss of social structures (42). His work addresses American federal regulations, claiming that "no sensible person can believe that circuses provide lions and tigers with a caged environment of 'sufficient space' to allow 'adequate freedom of movement'”. According to Tait and Ferrell, Regan's argument romanticizes an ideology of a human-free environment and avoids the consideration that humanbred performing circus animals display great intelligence with skills to produce complex 
maneuvers that even most humans cannot achieve. However, the criticisms of the lack of living space are valid and relevant to the touring performing animal.

For many, there is an ethical difference between the uses of exotic versus domesticated animals for entertainment purposes. As for wild animals, in the late 1980s, tour journalists and theatre critics occupied the middle ground of the politicized issue of animal performers. While some journalists wrote of their disagreements and disfavor, most made note that circus performing animals were bred in captivity and handled since birth (Bennie 10). These animals do not compare to the capture of wild animals that are forced into performing and touring for audiences. This argument could be made due to the active social use of animals. Breeding animals for circus performances is on the same continuum as breeding horses for competition and racing, as well as breeding cats and dogs for pets. Angela Bennie writes in her article, "The Circus Honours its Goal of Entertainment" about different aspects of human dominance over animals in the circus. She claims that the 'marvelous' tradition of the circus contains old ideological baggage as a display of man's dominance over nature - be it his body, the other members of his species, or the animal kingdom (10).

By the 1990's, exotic animal appearances started to diminish. According to PETA's online article, “We Never Gave Up: PETA's Triumph over Ringling Brothers” protesting animal performances continues to encourage the closing of many shows including the famous Ringling Brothers Barnum and Bailey's Circus after 146 years of performances. Many traditional family audiences find it difficult to picture a circus without elephants while modern eclectic audiences would rather not see any animals. With the rapid success of the touring hippodrama, Cavalia, it is clear that animal activist groups have been contradictory in attitudes towards performing domesticated animals versus wild animals. In May of 2016, CNN reported the closing of 
Ringling Brothers Barnum and Bailey's Circus elephant acts. Ringling toured with 13 elephants, and PETA and other groups were present on that first day of May. Featured in Faith Karimi's CNN article titled, "Ringling Bros. Elephants Perform Last Show" are photos of animal protestors, all holding signs regarding the termination of wild animal acts, not all animal acts. Karimi reports that lions, tigers, camels, horses, and dogs are all to continue performing for the show, however that all came to an end just the following year, as Feld Entertainment shut down the circus in 2017. The closing of Ringling does not only affect exotic animals. Ringling left humans and horses unemployed. Unemployed horses contributed to the equine 'wastage' issue, ultimately harming the welfare of horses.

While it is easy to picture a utopian world where wild animals and horses alike roam free, free from human restraint and manipulation, that is currently and historically not what the world is dealing with. Exotic animals have not always worked alongside of humans, but as previously mentioned, the horse has carried humanity to its modern advancements. The argument of space for wild animals somehow does not catch on with horses. If activist see a tiger in a cage, it is cruelty and negligence, yet if they see a horse in a stall, the horse is being taken care of. If we look at equine ethology, the study of equine behavior in a natural environment, we find that the horse is quite adaptable, for any type of domesticated lifestyle is far from the horse's natural design. Professor Jan Ladewig of Copenhagen University, author of "The Role of the Veterinarian in Animal Welfare" claims that the quality of a horse's daily outdoor routine matters quite a bit to the health and welfare of the horse. A stalled life fails to meet the physical and mental demands of horses. This 30 year old research study claims that horses are structurally designed to travel up to 20 miles a day to find food and water and a feral horse will do just that, while stabled school horses on average, receive 40 minutes of exercise, 6 days a week. Along 
with their need for space, a horse's long skinny intestines and constant production of hydrochloric acid are intended for constant grazing. As herd animals, horses are not naturally solitary and require social engagements. Also, horses sleep a mere 3-4 hours a day, not all at once, for that is all a prey animal needs as a deep sleep could be detrimental in a survival setting. Given the ethology and natural conditions of the horse, it is clear to imagine that habitat space would be a top concern in horse husbandry (1).

Humans have taken the horse so far from its natural contexts that it is common for the average equestrian to have a misunderstanding of the needs of the horse. Professor Jan Ladewig explains that although horses have been domesticated for hundreds of years, studies have shown that the domesticated horse does not differ substantially from the wild horse, such as the rare and endangered Mongolian horse, the Prezewalski's horse, either physically or psychologically. "Horses need physical contact with other horses, and social isolation prohibits the horse from engaging in mutual grooming, play, and simply just being near other horses they are bonded with. Most domestic animals are social animals. Socialization is almost a requirement for being domesticated" (1). Ladewig mentions a Swiss study found that 83.5 percent of horses from 12 different riding schools were housed individually and some horse owners did not allow their horses in group turnout, believing that injury was more likely in a group setting. Ladewig claims that domestication has not removed the basic social, physiological and psychological needs of the horse, and many management and living arrangements fail to meet these needs. Ladewig also suggests that if we are really concerned with the welfare of the horse, then horse owners should switch from individual housing to group housing. Species-specific needs can be met, and owners and managers can reframe their husbandry routines to increase the welfare of the performing and working horse rather than just getting rid of the horse and human working relationship 
altogether. Ladewig bids readers farewell with, "I hope I've made it pretty clear that what we need is much more information on how horses are housed, how much they get out either alone, and with other horses, and how much they are ridden" (1).

Adjustments to improve welfare are a more realistic and helpful solution for the performing horse. The hippodrama, when managed correctly, is a reasonable destiny for a working horse, keeping equines and artists active and employed. In comparison to competitions, rodeos, and horse racing, working in a forty-two-foot in diameter circle does not embody the same physical demands on the horse. While there are many studies on human related injuries in equestrian sports, researchers are gaining insight on the horse related injuries in sports and competition. According to Dr. Ed Kane, researching veterinarian and animal nutrition, working horses are predisposed to injury depending on the equestrian sport. Studies show that elite show jumpers had the highest proportion of injury at a distal location; the flexor tendon sheath, while dressage and elite event horses had more frequent injuries to the navicular bone within the hoof. Orthopedic specialists claim that as the sport horse ages and advances in its careers, there is a progression of problems including osteoarthritis, ligament problems, tendon injuries, hock injuries, back pathology, stress fractures, and other various injuries that are amongst the more common ones. Overall researchers suggest that horses competing in specific sports are at greater risk of injury, especially at a specific location, versus horses used for general purpose riding (Veterinary News DVM 360, 2014).

A major welfare concern regarding equine work load and safety are racetrack related injuries. When we compare the amount of death or injuries, it is clear to see that the equestrian circus is a far healthier fit for equine wellbeing. Dillon Mullan, writer for The Washington Post, reported the injury and death rate to horses used in equestrian racing. With such an early start to 
their career, racehorse deaths are at record numbers and effect horses at very young ages. On the third Saturday in May of 2016, 9 year old racehorse Homeboykris lost a battle to a fatal heart attack and 4 year old Pramedya died from a fracture to the leg. The sports world shook and attention was drawn to the ethics industry. These are just a few of the many deaths reported due to horse racing. Patrick Battuello, an animal activist, pulls daily reports from all national racetracks. In fact within the first 181 days of 2016, there were already 180 deaths, and sure enough that number was sure to rise. Through sending Freedom of Information Act requests, Battuello revealed that in 2015, 953 deaths were reported and confirmed of American racehorses, all for the enjoyment of gambling. "Every day we're killing horses for $\$ 2$ bets. Why do we still abide this in the $21^{\text {st }}$ century?" claimed Battuello, "We're so outraged about the Ringling elephants and the Sea World orcas, and rightfully so, but why not racehorses" (The Washington Post, 2016). Both of the issues regarding the Ringling elephants and the Sea World orcas tackle with adequate habitat space and exotic animal training for human entertainment purposes, however both of these arguments are not dealing with extreme fatality rates for human entertainment and gaming.

The physical impact of performing circus horses is much less demanding than a sport horse. Different acts and riding styles call for different tricks, but on average, the equestrian circus acts last from 5 to 10 minutes, usually with multiple horses switching off turns in the ring. As previously mentioned, activists believe in utopian ideology. Rather than shutting down operations, it would be more helpful to strive for more realistic results and solutions for animals currently living and working in such conditions. Research in areas of equine wastage illustrates this idea. Due to man's long history with the horse, horses are categorized as livestock and working animals rather than pets. While a horse can easily be considered a pet to many proud 
horse owners, realistically, a horse is a rather expensive pet. Money Crashers, a journal commonly featured in Forbes, CNN, The Wall Street Journal, and more, ran numbers on the average cost of owning, housing, feeding, and caring for a horse on a yearly basis, and even suggests ways in which owners can save some money through leasing and volunteer opportunities. Author Laura Williams wrote in her article, “Annual Cost of Owning a Horse and 4 Alternatives to Buying" produced the average costs of annual horse ownership of $\$ 3,876$ per horse, with a median cost of $\$ 2,419$. Data came from a survey conducted by the University of Maine. While horses can be a luxury item for the wealthy, for many middle-class Americans, horses assist in income, even if it is just to cover the costs of ownership. This can be seen in the form of lesson programs, therapy programs, livery and trail rides, farm work, performances, etc. In fact, the more a company can financially gain from a horse, the more security a horse will have in its home and the profits can often go towards feeding and caring for more horses in need. Many horses that cannot be rightfully placed in an ownership or working environment find themselves either neglected or sent to slaughterhouses.

While horse slaughter is a touchy subject in American culture, with 80 percent of Americans agreeing that horse slaughter is cruel and goes against the honor and nobility of the horse in American culture, eating horse meat is quite popular and seen as a delicacy in many Asian and European countries. Americans find ethical issues with horse slaughter, yet not enough horse enthusiasts are stepping up to offer homes and jobs to these horses headed for slaughter. According to Dan Lawler and L. Leon Geyer, authors of "The Horse Slaughter Conundrum", from the years of 2009 to 2014, more than 600,000 American horses were shipped to Mexico and Canada for slaughter (3). Director and producer of award winning documentary, From the Kill Pen, Sharon Boeckle, shares with viewers the demographics of horses that end up 
in kill pens, lots in which kill buyers purchase homeless and unwanted horses for very cheap prices, in order to make profit from selling them to a slaughterhouse. Of all the horses that end up in a kill lot, about 70\% are young Quarter Horses, 20\% are young Thoroughbreds, and 10\% are comprised of draft horses and mixed breeds. A surprisingly large majority are young and healthy purebreds that are simply out of a job. They are too slow for the track or they are 'too old' and not considered quality in the horse sporting industry to go on and breed after their working career. Sadly many western performance horses and racehorses are done with their working careers by age 8 ; horses live into their 20s and 30s. Equine slaughter is not just a trach receptacle, it's a business, a business which feeds into and allows for more mass production of sport horses, always offering a way to inexpensively dispose of unwanted horses, allowing more room for the breeding of more and more sport horses, in hopes that through all the wasted animals, they can filter through and find a few winners.

"Fired" horses, horses that have had their careers ended are only a fraction of those that contribute to American equine 'wastage'. Currently, around 50,000 wild horses, ones that never had the chance to work, are captured and held in the Bureau of Land Management's (BLM) 'holding pens' where they sit and await their fate, a gamble of death or survival. Unlike the competition or racehorse, Mustangs have no prior training or even handling, most are considered very skittish, fearful, and feral, and therefore have more obstacles in their way of finding a home or job. In the high desserts of Nevada sits nearly 16 million acres where 73 thousand wild horses roam and call America their home. With easy reproduction and a lack of wild predators, these overpopulated Mustangs are running out of space to safely maintain their numbers. According to Carolyn Kormann's article “A New Documentary Seeks to Capture the Plight of America's Wild Horses", in the beginning of 2018, The Trump Administration just shrunk the boundaries of two 
national monuments, removing protections of over two millions acres. Though for 40 years, BLM's round ups ups gather up these adoptable wild horses, yet only about 2,500 get adopted out. It is currently illegal to sell these horses to kill buyers, so right now there are about 50 thousand horses sitting in purgatory costing taxpayers about 50 million dollars every year to maintain their needs. However, last July, the House Appropriations Committee authorized an amendment to the Interior Department's 2018 budget that will allow the BLM to kill animals under their care. The Utah Republican Chris Stewart defended his amendment with the claim that the alternative would be starvation in the wild. Four months later, the Senate Appropriations Committee approved a proposal to give the BLM funding to explore more humane options including distributing contraception which will reduce wild horse populations. However, President Trump's 2018 proposed budget calls for drastic cuts to the BLM, leaving them only to sell horses to all types of buyers, including kill buying traveling to Canada and Mexico.

If horse enthusiasts and animal activists alike can agree that slaughter is just an inhumane cover up to an industry problem and does not offer a viable solutions, and equestrian sports careers can be dangerous and a gamble to assure a true home, then maybe running away with the circus is not such a terrible option after all. Unlike many equestrian sports, circus horses are privately owned rather than company owned or sponsored horses. Rather than a prospecting investment, many traditional circus performers consider their horses as lifelong partners. According to the webpages of Cavalia and Big Apple Circus, successful equestrian liberty circus performers Sylvia Zerbini and Jenny Vidbel both offer their home as a retirement place for their performing equines. Rehoming horses in private entities that assure a life-long home and giving them a less demanding job could be a great solution for ex-racehorses, retired western performance horses, and even wild horses. David Phillips, a reporter for the Times, recently 
wrote a book titled Wild Horse Country. At the turn of the last century, a Mustang named Hornet ended up as a member of a theatre troupe. Another rehomed Mustang was noted to be sighted pulling a cart near Coney Island, New York, but spent his summer afternoon at the beach with his owner. Sadly, most Mustangs did not end up in such great scenarios.

While there are animal activist groups currently fighting for the protection of wild horses, racehorses, and competition horses, many people do not know that historically the circus has been a rather safe haven for horses and circuses have actually fought for equine welfare. It is possible to consider this true in modern society. Phillip Astley, our father of the modern circus, trained his horses in a much more humane way than what the current style of horse training was for the era. According to Katie Lavers, author of "Horses in Modern, New, and Contemporary Circus", Astley campaigned a more humane way of training, especially for a time when the horse was a battle and transportation object. Astley's circus acted as a social force to contest pervasive cultural attitudes towards horses as machines. This new attitude and lifestyle with the horse developed from cavalry men, including Astley, who were relying on their communication with the horse as a means of survival. Experiencing intensities of battle created an outlook that included the horse as an extension of man's own being. In John Berger's article, "Why Look at Animals?" he suggests that a shared relationship between humans and animals is due to the shared sense of mortality (62). Industrial society lost these experiences, but the battlefield was where this shared sense of mortality could still be found. Dennis Wheatley's autobiography paints a visual picture of his memories as a solider during World War I on the Western Front in 1915. "There were dead horses lying all over the place and scores of other were floundering and screaming with broken legs, terrible neck wounds or their entrails hanging out” (24). Such 
intense experiences of shared mortality emphasized the close bonds that ex-cavalry men/future circus performers shared with their horses.

Lavers provides historical insight into the activity inside Astley's Amphitheatre in her article "Horses in Modern, New, and Contemporary Circus". Astley's circus served as a message to honor and protect the horse. In his act called "Prologue to a Dead Horse" a horse lies at his feet motionless then rose up to serve and protect his general. Astley also created the liberty act and it is still highly popular in modern equine entertainment (148). Here the trainer or performer guides the horse with no rider or equipment. At the time, the liberty act was very unique for an era when the horse was solely used to serve and work for humans. Both watching and performing a liberty act develops feelings and emotions of a more empathetic and less exploitive relationship with the horse. In both the old and new equestrian circuses, a liberty act represents partnership, shared willingness with a coax of kindness and reward. What makes an act like a liberty act so powerful, and a great counter argument towards modern animal activist groups is the idea that a liberty horse has agency. The horse can choose to perform a maneuver and received a reinforcement reward, or they can opt out of cooperation and receive a form of punishment. Punishment would frighten off a liberty horse and the horse will not return to the trainer, as they are not tethered. Agency in the liberty horse is limited; however, this is more agency than in other equestrian disciplines where when a horse tries to take an alternate option, immediate physical pressure is applied, closing the door to any alternative choices. Astley’s reinvented curveball to equestrian arts has included the horse in the narrative and is the defining origin of horsemanship, horse and human relationship.

Partnership is the horse's only chance at a good life. In today's society, Cavalia, an entertainment company founded in 2003 specializing in modern productions of equestrian circus 
acts from Montreal, put this idea back on stage and in the ring with a modernized natural theme to it. The reason this is so important to the welfare of the horse is that horses are still considered livestock, regardless of how widely popular they have become for sport and leisure. According to Katie Lavers, the image of the horse is both confusing and conflicting. Wild animal, livestock, and companion are the major categories that horses are commonly grouped into. Deciphering what category one views the horse in will ultimately define what kind of ethics and treatment the horse will receive. Horses are one of few animals that embody all these groupings at once. In both the United States and Australia, many wild horse populations still exist, as recently mentioned. The governments of both nations classify the horse as livestock; however the vast majority of horse owners, riders, and enthusiasts consider them as a companion animal, raising constant controversy.

In 2013 in Australia, at the same exact time that Cavalia was wowing audiences at high sales costs to perform their displays of peace and friendship with the horse, The Australian newspaper published a story in which 10 thousand wild horses were killed at Tempe Downs Station, in the Northwest Territory of Australia (Gilonna 19). The same issues currently exist in America. A 2013 article in the Los Angeles Times published a story on a mishap in Reno, Nevada regarding the public controversy at the BLM's mustang round ups. 23 horses were brought to auction from a round up (19). Nervous and frightened, the horses, some mares with foals at their side, anxiously paced in their enclosures while two main groups of people watched. Glionna writes, "In the crowds are so-called kill buyers scouting product to ship to a foreign slaughterhouse. Also on hand are animal activists who, check book in hand, plan to outbid the kill buyers. The mood is prison-yard tense, with armed state Department of Agriculture officers are looking on". 
Grouping circuses with kill-buyers is the incorrect association. Sadly, this is the viewpoint of many activist groups. While some see the contemporary Cavalia as a magical production that spotlights the beauty of a horse and human relationship, every coin has another side. Kim Baston was present at a 2013 production of Cavalia in Australia and writes of witnessing "an animal trainer having his sad subjects, bent low, file past" (22). This author did not see a seamless display of partnership, but rather a continuous exploitation of submission. Horses required to kneel and to lay down in submission paints the trainers of Cavalia no different than any other type of exploitation from the horse. Baston claims that the audience is presented with a succession of tricks demonstrating the mastery of one species over another, the mastery of humans over horses.

The outlook on the idea of any human and animal relationship is a topic that never seems to end nor come to any agreement among all people. While ideals may always clash, and viewpoints are drawn from perspective, insight, and experience, one must draw the line somewhere. Phillip Astley, and Cavalia's Frederic Pignon and Sylvia Zerbini's displays of dominance over another species can also be interpreted as displays of ethical horse training, creating a bond and dialogue between horses and humans that is mutually beneficial. The horse performs tricks for which they are humanely trained, while the human provides shelter, food, water, and security; the horse lives under the protection of a familiar human and never fears for its life from natural predators, and never competes for resources. As researched, no sport, working, or competition horse are safe from injury, cruelty, and fatality, and neither are truly wild horses. Therefore where is the line drawn for what is the best future for the horse?

It is quite clear and easy to say that the horse has come very far. From instrumental transportation use, to war vessels, the industrial revolution both saved and killed the horse. A 
utopia where all horses run wild and free from human harm is just not a current realistic vision. The father of modern circus brought more humane horse training and partnership into the limelight, and his platform of the circus is currently under attack from those who want more for the horse, yet, what are the alternatives? Most horse owners do not possess the financial stability to provide all care, feed, land, and expenses for the horse with nothing to ask from the horse in return. If asking for some time teaching and performing some tricks in a humane way is harmful, then sadly the horse will never catch a break. Weighing realistic options and researching the harmful sides of the equine industry will only bring attention to the fact that just perhaps the circus is a beneficial option for the horse. Data can be used in open communication with animal activists groups before one of the last remaining safe industries for the working equine disappears.

Circus originated as a social force to contest ubiquitous cultural attitudes towards horses as they were commonly thought of as beasts of burden and as machines. Modern circus acts as a social force to contest the modern perception of horses as money makers; both in detrimental races and competition and the fatality of human consumption. If regulations were applied to assure more roaming space and social herd settings for performing horses, the circus can be an ultimate safe haven to horses; respecting their ethology and natural design while employing the horse, providing life and purpose. If a horse performs in an equestrian circus for the purpose of education and aesthetics to the public, than historically, the horse would be in its highest degree of welfare to date. The circus stands up for the beliefs and benefits of the horse and it actively provides horses worldwide with suitable lifestyles and kindness, as Phillip Astley's golden rule notes, "Mad men and mad horses will never agree." 


\section{CHAPTER II: DIFFERENCES IN PRODUCTION THEMES OF THE OLD VERSUS THE NEW EQUESTRIAN CIRCUS}

Glitter, top hats, whips, and over-the-top glam are the main imagery associated with traditional circuses. Companies such as Ringling Brothers Barnum and Bailey's had portrayed circus in this way for 146 consecutive years. All other companies hold true to the over the top traditions of circus glamour, while new age presentations such as Cirque du Soleil put on a new artistic twist from the traditional theatrical elements. New artistic visions such as original makeup and high fashion costumes, original music usually sung in foreign languages, and abstract stage settings cover the same types of acts seen in old circus. The physical acts and tricks remain the same; however the theatrical elements make the two forms of circus, worlds apart. Stripped down to naked performers in a yard or gym, the two acts would be similar, yet ticket sales and production themes separate these worlds. It would be incorrect to say that ticket sales and attendance are based on talent alone. The same holds true for the equestrian circus. In order to make proper changes in an attempt to save the equestrian circus, this chapter will examine theatrical elements of traditional equestrian circus acts in comparison to Cavalia: A Magical Encounter between Human and Horse, a show with artistic vision that brought popularity back to equestrian theatre but also widened the gap between modern and traditional equestrian circus.

Cavalia is a touring theatrical horse show that features various equestrian acts commonly found in the circus. As of 2018, Cavalia is touring the United States with its new show Odyesseo. Cavalia, the original production is currently in China also touring with success. According to Elizabeth Ann Peer, writer for the Marin Independent Journal, the shows' president and artistic director, Normand Latourelle, never expected his show to gain such rapid 
popularity. Based out of Montreal, the premiere of Cavalia in the big top took place in October of 2003. Latourelle gained inspiration from the artistic visions of Cirque du Soleil with an understanding that historically, Americans expected animals as part of a circus show. Latourelle found vision from French horse trainer Frederic Pignon and his wife Magali Delgado. Frederic and Magali are widely known for their strong bonds with their homebred horses, displaying exquisite acts of liberty and dressage without equipment on beautiful white Andalusian stallions with long flowing manes and tails. "I knew that I didn't want to take advantage of the animals, and Pignon played with the horses and didn't constrain them," said Latourelle in his 2004 report with Peer. The aim of Latourelle's Cavalia was much like the aim of Cirque du Soleil, to reinvent traditional circus in a modern and artistic way, with mutual trust between the horse and his rider. "When (the horses) don't feel they are going to be attacked, they are calm," Latourelle says, "It is possible to work with respect with the horses" (Peer, 2004).

Taking place under an enormous white big top tent, Cavalia is aimed to a wide demographic and has performed in major cities. In 2013 a reported 3.5 million people saw the production, and this was before the release of Odysseo, their second touring production. As witnessed and reported by Kim Baston in her article, "New Hippodrama, or 'Old' Circus?: Legacy and Innovation in Contemporary Equestrian Performance", the 2013 production Baston attended in Melbourne, Australia, presented many theatrical elements that represented themes of equality. In the rectangular stage, a circus ring would appear for certain acts. A larger screen would project various environments, and images of a hologram horse would appear on occasion. There was a large cast of acrobats and actors including a band and singer, all wearing loosefitting earth toned wardrobes. Within the tent, there were opportunities to purchase horse-related merchandise including clothing, mugs, plush toys, artwork, and grooming supplies. Premium 
tickets admitted guests into the back stage warm-up arena and stabling area. Acts featured include both riding and ground work such as high school dressage, bareback/rosinback vaulting, voltige/trick riding, liberty, drill work, roman riding, jumping, and even some non-equine related circus acts such as aerial bungies, silks, acrobatics, and rolling globe. With a dream like setting, Cavalia paid tribute to the horse as an equal partner.

In fact, as Baston goes on to describe, Cavalia even tends to stray away from the traditional concept of "circus". For example, rather than considering the production to be an equestrian circus, the program goes on to describe the piece as an "equestrian ballet" or an "equestrian poem". Their big white tent is described as a white cathedral or castle, avoiding the words "tent" or "big top". During the day, before show time, horses are worked, what a usual practitioner would call a "training session." The language of Cavalia calls these moments "workshops". Their vocabulary includes calling "turn-out", and "outing", the time when a horse can be loose to run, stretch, and enjoy time out of the stall. The program for Cavalia ensures that every horse is on stage for a max of 12 minutes total and that there are understudies in case of injury or overworking. They stress that their equine stars are quite pampered with massages, outings, and routine veterinary onsite care. By using theatrical elements and eloquent language, Cavalia certainly paints a picture to their audience that they are not to be confused with an equestrian circus, and it works. According to their website, ticket prices range from $\$ 40$ with an obstructed view to $\$ 270$ with their VIP package (12).

When we compare the elements of Cavalia to traditional circuses involving equestrian acts, we see, hear, and feel very different things. Robert Sugarman, author of the article, "The New Circus: The Next Generation" provides readers with the different themes, costs, and appearances of traditional circuses. Sugarman claims that the new circus is getting smaller and 
more intimate; transferring from three rings, down to one, ticket sales are going up and the setting gets smaller, as we see in Cavalia. Ticket sales were once affordable to all, but now 'new' circuses such as Big Apple Circus, are selling for $\$ 65$, and easily starting at $\$ 100$ for a theatrical Cirque du Soleil production. Big Apple Circus changed to a non-profit format, centralizing the focus of the city it was home to, however, the production closed in 2016, under long tern ownership of Paul Binder and previously with his separated wife, Katja Schumann (431).

According to circus historian Dominique Jando, Schumann, born in Copenhagenm Denmark from a German family of equestrians who maintained a rich and reputable history with performing horses in the art of high school dressage. Performing from the age of 10 in her family's Cirkus Schumann, Katja went on to succeed as a female solo rider. In 1947, she participated in the first International Circus Festival of Monte Carlo, a festival held each year in mid-January in Europe, hosting twenty-five of the world's greatest circus acts competing for the champion title and award of golden clown. In that festival, she won the La Dame du Cirque award, given to the best female performer at the festival. In 1976, she won a Gold Medal at the Circus World Championships in London. Though Schumann is a master of various forms of riding such as roman riding, rosinback, and liberty, her family's specialty act is the art of dressage. Dressage involves riding dancing horses, performing high step maneuvers, and aerials above ground; high school dressage is one of the oldest forms of riding. All maneuvers are natural gaits to stallions preparing to fight or mate and were trained under saddle as battle tactics. Dressage is performed under saddle or in harness, rider in tall boots, a tailed coat and top hat, using whips, spurs, and bridles with bits, and on frequent occasion, double bits.

With the reforming of Big Apple Circus, new equestrian acts are taking place of the 'old' circus equestrian acts in order to fulfill audience preferences. Jenny Vidbel is a veteran 
performer for Big Apple Circus. For over six years Jenny was employed as the animal director and equestrian artist after Katja's divorce and termination from the production. Jenny arrived at the time that the show was trying to put a new face and appearance in order to gain more attention, transforming from 'old' circus to 'new'. Her act was not selected at random, but for the theme in which it comes with. Rather than using battle tactics and domination, Jenny's large liberty acts represent partnership and honor as her black and white horses dance around her, free of harness. With just a whip in hand to signal cues, not as punishment, Jenny's horses largely outnumber any current modern liberty act. Like Cavalia, harness free horses represent freedom and unison as they perform patterns with no restraint.

Big Apple Circus is now following the footsteps of Cavalia both in the ring and the reforming of their language and outside appearances. Cavalia has an "adoption" program for horses that either retire from the show, or don't work out. The title of 'adoption' could in theory; just replace 'sale'. The horses that are for adoption are not to leave without an adoption fee, but promoting themes of equality, the term 'adoption' is yet again a wiser word choice for eclectic audiences. Kenneth R. Rosin of the New York Times interviewed Jenny at her mountain farm home in upstate New York in January of 2017. In his article "Retired Big Apple Circus Animals Prepare for Their Second Act", he interviews Jenny to find answers to modern audience concerns such as "What happens to the retired horses? Do they become euthanized?" Jenny replies with "They retire and that is it. I'm going to give them this in return for their whole life and make sure they have a great retirement." However this article goes on to explain that the animals will not be in full retirement, for they are involved in a therapy program that pairs horses with children with special needs, economically disadvantaged youngsters, and older people at their upstate retreat. In fact, the article mainly focuses on the new and upcoming program that the circus will be 
involved with. The facility will eventually feature an amphitheater featuring equestrian performances. The upcoming nonprofit rehab program and the Windham Mountain Horse Theatre will be run by the $\mathrm{Al}$ and Joyce Vidbel Foundation, along with Gary Dunning, the former executive director of Big Apple Circus, and Guillaume Dufresnoy, the former artistic director on the board of directors. The article is full of photos of smiling people and horses enjoying their outdoor habitats. Jenny is not the only horse trainer to open a theatre at home. Sylvia Zerbini, another liberty trainer did so in order to supplement income following the loss of job opportunities from the industry's downfall. While there is good at the heart of this project, the positive publicity that comes surrounding positive themes affects followers, and in turn, ticket sales.

Just like Katja Schumann, Jenny Vidbel was also born into a circus family. In the October, 2017 re-opening of Big Apple Circus, and the re-hiring of Jenny Vidbel, her new liberty act features 3 large black horses, 3 large white horses, 6 black ponies, 6 white ponies, and one black Friesian ridden in the center, with all the liberty horses free from harness. Through archival research through Circopedia: The Free Encyclopedia of the International Circus, videos and photos show that Jenny's initial liberty act with Big Apple Circus differed greatly from the 2017 version. In the early years of 2010-2016, her acts featured both in harness and free of harness, depending on the seasons. At times her hair was long with extensions and the costuming was very colorful and glamourous, complete with a long ringmaster coat and top hat. Under ownership of Binder, Jenny featured multiple acts. Along with her liberty act, Vidbel worked her mixed animal act and dog act. Liberty would be, at times, free of harness while mixed animals (llamas, camels, and ponies) would all be in harness. Harnesses were complete with bits checked down to keep heads tucked in and feather plumes on the top of the head, as 'old' circus tradition 
would feature. Searching through the archives of Circopedia, Katja Schumann's liberty acts were always run in harness, until recent years when working with natural horsemanship trainer. In the new 2017 production of Big Apple Circus, Vidbel's horses are free of harness and she proudly wears her usual short hairstyle while wearing a black and white dress, to match her horses (circopedia.org/Jenny_Vidbel).

Another shift in themes has occurred not necessarily within a show, but for the artists themselves to stay current and employed with the changing demands of circus audiences. A prime example of this can be seen in the acts of Sylvia Zerbini. Zerbini was born into a circus family of nine generations of performers, her father, Tarzan Zerbini owns and runs the Zerbini Circus, a Shrine tent and arena variety show that tours all over Canada and the United States. Zerbini has performing siblings and cousins, all involved with equestrian displays, yet within the family, no one has the same fame with horses as Zerbini does, and that is due to her change in themes with her liberty act. According to her website, Sylvia Zerbini and her Amazing Horses Grand Liberte, she spent 6 straight seasons (2002-2007) performing with the Ringling Brothers Barnum and Bailey's Circus where she mixed her talents of both liberty and aerials. In the traditional multiple ring setting, she wore glittered leotard as she hung from a lyra while her white Arabians danced below her, all in bridles. Her career with Ringling included Feld Entertainment's Kaleidoscope. According author Lawrence Van Gelder of The New York Times, the shows was a one season wonder (1999-2000). An American circus that combined European circus styles with influence from the contemporary circus movement. It was Ringling's first tent show with only one ring in over a century and was quite successful and would be "hard to top" as stated in Van Gelder's 2000 article, "Circus Review; Three-Ring Thrills Distilled into One". Regardless of the success, the tour could not overcome the costs of moving a tent to the major 
areas it toured in. Kaleidoscope was a stage where Sylvia again wore a very glamourous and colorful robe and her horses in white sparkly bridles.

Cavalia's single stage and massive tent have successfully moved to major cities since 2008, and as mentioned, is still doing so with two units. This is not by chance, or coincidence, but due to success from the production itself. As stated on Zerbini's website, Normand LaTrouelle saw Zerbini perform in Lake Placid, NY in 2007 and hired her right on sight to feature her liberty act. Normand once quoted, "I went all over the world, and there is only one Sylvia Zerbini!” Working alongside Frederic Pignon, Zerbini was in charge of all liberty acts and created her choreography herself. As the featured liberty act, Zerbini performed on Cavalia from the beginning in 2008 to 2011 . Her choreographed act can still be seen on set today, yet with a different trainer and different horses. Zerbini performed in brown or earth-toned baggy-clothes, and her hair was down and almost dreaded or sometimes just braided. As for her horses, free of any harness or bridle with manes flowing loosely. The backdrop of the stage was a forest and the ground was sand. The music consisted of acoustic guitars quietly playing. Her act can been seen on her website, her horses entered the ring one by one, allowed to move freely, play with one another, groom one another, and browse around. Zerbini enters and walks around, greeting each horse individually, cueing for tricks from each horse such as rearing and bowing. She then proceeds with her large group liberty maneuvers, in the same manner as featured on Ringling just one year prior.

After her tour with Cavalia, Zerbini has gone on to working in equestrian-only theatres and events. Shifting from 'old' circus to equestrian-only theatres has transitioned her name from the elephant riding Shire circus family to well-renowned horse trainer in the industry of equine practitioners. As stated from Sylvia Zerbini and her Amazing Horses, in recent years, Zerbini has 
performed at events such as Equine Affair, BreyerFest, Del Mar Night of the Horse, Sable, Arabian Nationals, World Horse Expo, etc. The only 'traditional' circus that Zerbini has performed in since her leave from Cavalia is with the Circus Arts Conservatory, a nonprofit circus that is one ring during the winter season, which is the 'off season', in Sarasota, Florida. Zerbini currently resides at her Grand Liberte Farm in Ocala, Florida, only a few hours from Sarasota. Sylvia has been featured in magazines and websites such as The Chronicle of the Horse which caters to the equine sport industry, not entertainment. According to the American Horse Council, the horse industry contributes approximately $\$ 39$ billion in direct economic impact to the United States economy and supports 1.4 million jobs on a full time basis. When indirect and induced spending are included, the industry’s economic impact reaches $\$ 102$ billion (horsecouncil.org/resources/economics). She teaches lessons and clinics out of her Ocala farm and produces weekly shows in her equestrian theatre on her property when she is not on the road. Sylvia Zerbini is likely to be one of the only circus performers known in the equestrian industry. Due to a change of theme, she has made her way into the bigger bucks of success as the halftime entertainment in equestrian sports rather than remaining center ring in an industry than almost no longer exists.

It's hard to believe that themes of 'old' equestrian circus are becoming extinct. It is not the art of equestrian circus itself that is disappearing, for the same artists, such as Sylvia Zerbini, are shown in both the 'old' and 'new' displays. Ringling Brothers Barnum and Bailey's Circus, where Zerbini actually spent more years performing, is now out of business, and Cavalia is growing more and more successful by the minute. This change in color schemes, attire, scenery, and equipment all contribute to the growing theme of 'playing' with horses rather than 'working with' horses. The success of this theme aimed towards both the general public and horse 
enthusiasts gave viewers a piece of something the average person could not easily accomplish, 'befriending the beast' rather than 'taming the beast'. Humans, the top predators, can create any tool, or outwit any animal into cohesion, but gaining voluntary participation from a large creature? This is the new "wow" factor, since the contrary has already been done before, in many times and in many ways. Cheryl Laird and Sandra Oliynyk wrote an article on the theme of Cavalia upon its 2008 opening for Practical Horseman called “'Playing' with Cavalia's Horses". The article starts with, "The co-directors of the critically acclaimed equine theatre share ways to help you establish trust and communication with your horse." The authors go on to state that the horses of Cavalia are not trick ponies submitting to the will of their handlers, but are trained with equality. The interview with Frederic and Magali go on to giving tips on training and relaxation with their horses.

In their book, Gallop to Freedom: Training Horses with the Founding Stars of Cavalia, a little background is given on our star trainers, Frederic Pignon and Magali Delgado. Frederic was a trick rider during his younger years, and his wife, still a Grand Prix dressage rider who competes. Both of these disciplines come from ancient military tactics. Man's long history of using the horse in conquest expresses themes of dominance and power rather than friendship. Kim Baston's review of Cavalia indicated that there are other acts besides liberty. In equestrian circus arts such as trick riding, dressage drills, and rosinback, the horse is an instrument rather than included in the narrative, and are clearly under human control. All of these acts include bridles, saddles, whips, etc. In fact, as mentioned earlier, Frederic Pignon's 'playtime' with the white stallion looks a lot like Phillip Astley's comedy act, "The Tailor Rides to Brentford" in which the horse has a major role in the narrative. The difference of 'chase' and 'follow' simply lies in the theme of the narrative rather than the training or the act itself. 
How is it that just the production themes that are altering audience perceptions, and in turn, ticket sales and success of the show? What goes on inside the tent and outside of the tent both contribute to the theme of the show. From backstage tours, the detailed program, the training books and home-based Montreal training center, Cavalia's theme of equality is rather apparent in all other aspects of the job. Frederic and Magali claim to use 'ethological training', however Paul McGreevy and Andrew McLean, both researchers of equitation studies and equine veterinarians, note that this term is becoming increasingly popular among equine practitioners and trainers but there is a lack of clarity over its usage, as stated in Baston's review of Cavalia. In their article, "Ethological Challenges for the Working Horse and the Limitations Ethological Solutions in Training", McGreevy and McLean explain how there had been a new and popular attempt by numerous practitioners in the equine industry to brand 'ethological training'. Ethology is the study of animal behavior in a natural environment. Studying an animal's ethology can help humans understand how animals respond to environments in which they have no evolved in, such as the human-made domain. This developing science allows humans to gain insight as to how natural selection has shaped behaviors and also helps humans predict how horses may react in a human environment. McGreevy and McLean report that ethological science studies contribute to "effective and enlightened training" but are not itself a training system or philosophy.

In fact, researchers are reporting that equine training where a human claims that a horse will 'submit' into 'dominant leadership" is just an anthropomorphic claim. Understanding what scientists like McGreevy and McLean have studied, horses simply learn through classical and operant conditioning. This idea of a visual 'relationship' between horse and human is just a theme around a display of a horse responding to learned and refined cues. When we look at 
Phillip Astley's training, we really don't see much of a difference in actual techniques. In his book, Astley's System of Equestrian Education, readers can gain first hand insight into the training methods from the father of modern circus himself. A manual explaining the importance of science in horse training, Astley's work goes on to explain his general horse training principles.

"Thus it is necessary that their tutor or instructor should possess sound judgement; because those who treat them with severity; they obey with the greatest reluctance; while on the contrary, all who treat them with tenderness, will assuredly be repaid with the utmost gratitude and most implicit obedience" (6).

Both Cavalia's head trainers and Phillip Astley claim to not use non-forceful horse training tactics, yet both possess flawed ideology in an ethological perspective, holding the horse to higher anthropomorphic thoughts, such as honor, partnership, leadership, etc. Cavalia's 'ethological training' raises challenges given the very unnatural working and living environment of their or any performance horse. If ethological training is based on a horse's behavior to their natural environment, then it would be quite difficult to judge aversions from an ethological perspective if the humans are putting horses in circumstances of inappropriate pressure, like the stress of a show. If training methods do not vary greatly in the long history of the hippodrama, nor do the acts themselves, then it is solely the differing 'themes' of hippodramas that have an impact on the success or failure of a show.

The recent and successful change of theme in equestrian circus all happened as part of an attempt to satisfy the growing eclectic tastes of modern audiences. After all, the success of a show is simply a representation of profit, coming from the amount of seats sold at a production. In their article, "How to Engage Audiences with Increasingly Eclectic Tatstes: The Experience of 
TOHU, a Montréal Circus Arts Presenter", Andre Courchesne and Philippe Ravanas explain how TOHU, the Circus Arts City, a theatre space and home to international circus festivals, is facing new challenges with presentation themes in order to serve their audience. With a desire to keep a traditional image of circus, about $40 \%$ of their customers are young eclectic consumers (81). In Western culture, the traditional circus is strong due to its association with popular parent-child activities. Based on clowns and animals, traditional over the top glitzy circus is rooted both aesthetically and ritually into Western culture. While wanting to hold true to family traditions, TOHU had to grapple with the recent popularity of creativity over tradition. From a recent 2013 survey of TOHU's audience in Montréal, circus capital of North America, data showed that 55\% of their audience is under 45 years old, highly educated with higher than average income, and $69 \%$ were women. In fact, their consumer basis was split into 3 main groups; as mentioned earlier, young eclectic consumers at $40 \%$, performing arts attendees at $28 \%$, and family-oriented customers at 34\% (85). Young eclectic customers had a high rating of Cirque du Soleil attendances along with museums, concerts, and dances. Performing arts attendees had high attendance numbers at theatre productions, and music events, and low attendance numbers for clowns with the lowest rate for animals. While this is a sample from a major city like Montréal, the family-oriented customers are a demographic looking for family discounts and child prices, neighborhood offerings, and entertainment during school breaks and weekends, sharing educational and environmental concerns. While family tradition is a goal and concern for 'old' circus, based on both the data of income quality and quantity, traditional circus will only cater to the family-oriented customers who don't want to spend a lot of money, nor does their demographic have the numbers to fill the seats. 
Cavalia's success may just be the most modern version of the 'old' circus vision; go to the people and show them what they want to see. So Cavalia travels to the largest international cities with the largest base of high income consumers and they deliver exactly the kind of show that the target demographic wants to see, and for a much higher price. They do it, and they do it well, but how? Now that we understand that equestrian acts are no different in 'new' circus than they were in 'old' circus and that training methods have not differentiated, then what exactly is it about these new emerging themes that sell so well? In "Marketing Animal-Friendly Products: Addressing the Consumer Social Dilemma with Reinforcement Positioning Strategies", Lenka van Riemsdijk et. al. argues that customers are leaning towards animal-friendly products due to ethical and social values (11). Consumers have the free choice to accept or reject any type of product that may be animal-friendly, whether it be a cosmetic, food, or even a live action production. Modern production has marketed animal-friendly with feelings of values, healthiness, and an altogether good feeling. When one is purchasing something animal-friendly, they are able to put their money towards something that they are led to believe will be helping animals rather than harming. This conceptual ideology holds true for entertainment such as hippodramas. Cavalia's theme of equality is their marketed selling point. Audiences can purchase tickets to Cavalia where the horses are stars, performers, and equals, or tickets to Ringling Brothers Barnum and Bailey's Circus where animals are working instruments for entertainment.

Unfortunately lines get blurred on what is fully true to be animal-friendly. When a circus is advertised, the theme of the show is marketed to the public, in hopes they will enjoy the sample of what they see, and will purchase tickets to see the rest for themselves. Daring displays of horsemanship have entertained audiences for centuries, and will continue to do so, but under 
the rules of those who will pay to see such displays, thus no longer just supporting 'the art' but specifically the 'kind of art' in which they choose to trade their money for. 'Old' circus stands by their theme of family, fun, and tradition. In the early years, the 'old' equestrian circus represented the amazing things a human can do on or with a horse. Society viewed the horse in an instrumental way, and that theme carried into the ring. The 'new' equestrian circus represents the same historical physical displays, but in a manner of what a human and horse can do together. First world society no longer views the horse in an instrumental fashion, and they no longer want to see horses as an instrument when being entertained. The equestrian circus plays by the rules of supply and demand, and due to modern marketing strategies, the traditional equestrian circus is knocking on deaths door while it also experiences rebirth in an equestrian ballet such as Cavalia. If we peel away these layer of production elements that color in this new contemporary theme, and we pull apart the glitter, feathers, and glory of the old fashion circus, we see the same framework of training methods and tricks for all specialty equestrian displays. Performing equestrians have no choice but to give the people what they want if they want to survive and keep a paycheck coming. But the audience also has a responsibility to research what they do not know, for they are being just as fooled by the new fancy labels and charming terminology. In the end, the hippodrama is just form of modern live entertainment which will succeed or fail based on the approval or disapproval of its target audience, so in the words of Coach John Wooden, "it's not what you do, but how you do it." 


\section{CHAPTER III: IMPLEMENTING PROPER TRAINING TECHNIQUES TO PROMOTE}

\section{WELFARE}

The working performance horse was not born with the innate ability to perform in front

of an audience. Many hours and many different types of training methods shape the performance. All horses learn at different rates, have different personalities, backgrounds, fears, and talents. Finding the right horse, with the right traits, age, and ability is just the first step of creating an equestrian act. Applying proper methodology for the particular animal for a specific task is a science in itself. Master horse trainer Michael Bevilacqua, author of Beyond the Dream Horse, describes horse training as working with a young child who does not speak the same language as you (26). An equestrian act is a live dialogue between a horse and a human. Every horse, in every act, in every show will have a varied response to their environment. No two shows will run the same when working in open dialogue with a horse, and every bodily gesture, word, and tone has a different meaning for each specific situation. An equestrian performer has to know what to 'say' when a horse raises concern or question in order to produce choreographed routines in performances. A rider or trainer acts as a problem solver, a leader, and a translator all while also attempting to appear flawless to an audience. How an audience views the onstage communication is an added element of the act. While spectators may find it intriguing to witness that interspecies conversation on stage, some may be turned off and disconnected by the sight of the communication tools. However, when training and performing are executed properly, the circus can be a safe haven for horses.

To understand what is viewed on set, one must first understand how the language is created, what is going on with the cognition of the horse, and the response of the human. By studying equine cognition, we can develop methods that make the most sense for the horse, thus 
improving welfare for the performing horse. We must first look at their mental capabilities. Researchers Kendal and Premack argue that horses have a poorly developed pre-frontal cortex; this prevents them from being able to develop abstract thoughts (13). With that being said, we understand that horses only live in the moment. They are unable to think about the future or the past. Memories are triggered by some sort of environmental stimulus. This would explain why horses create habits of continuous spooking at the same spot in a particular environment. Horses also lack the ability to solve problems. Learning is only through trial and error. Interestingly enough, veterinary researcher Wolff and Hausberger argue that horses have excellent long term memory on the flip side, a 2008 study by Andrew McLean shows us that their short term memory is very poor (76). Most trainers can say that they witnessed at least one horse that possessed a learned fear from an incident long ago. That learned fear from their long term memory tends to overshadow all of that recent desensitizing and retraining. All of these discoveries of equine cognition should be taken into consideration when formatting a training method.

Gemma Pearson, practicing and researching veterinarian with specialty focus in equine cognition and applied learning theory, gives readers some easy to follow insight on the learning patterns of horses in her two-part article, "Practical Application of Equine Learning Theory". Gemma breaks down the ways in which horses learn, both from their environment and from trainers. Horses simply learn through applied learning theories (252). These include operant conditioning: a behavior influenced by a type of reinforcement, classical conditioning: associations between two events, and habituation: involves elimination of a response to a stimulus in their environment. 
There are four different type of operant conditioning strategies in which horse will learn from. First, there is positive reinforcement. Positive reinforcement is the addition (positive) of a stimulus in order to increase (reinforcement) a desired behavior. This can be a treat or a scratch in order for a behavior to occur again. Next, there is negative reinforcement which is the removal of a stimulus (negative) in order to encourage a behavior to continue (reinforcement). This can look like the removal of leg pressure to get the animal to move forward; or the removal of rein pressure when the horse stops. Then there is positive punishment which is the addition (positive) of a stimulus in order to end or eliminate a behavior (punishment). This can look like a smack to stop a horse from biting or kicking. Finally, there is positive punishment, the removal (negative) of a stimulus to end or eliminate a behavior (punishment). This can be viewed as the removal of a feeding in order to stop a horse from behaving badly under saddle, or removal of a mare from a stud behaving with spirit.

Aside from operant conditioning, there are other ways in which horses learn from training tactics or from their environment. Is the process of making associations of two previously unrelated events. Does Pavlov's dog ring a bell? While studying digestive physiology, he noticed that the dogs would start salivating when he rang the bell to signal that it was feeding time. They would salivate at the sound of the bell even though there was no sight or smell of food. They learned to associate the bell with food through consistent associations. Horses are great at classical conditioning.

Operant conditioning allows the horse to control their environment while classical conditioning allows for predictability of their environment. This is so important for their survival. For example, the boss horse pins their ears and takes actions to demand that everyone moves out of his way through a series of kicking and biting. It does not take long for the 
subordinate horses to associate the pinned ears with the dominant action. The herd quickly learns to move away (conditioned response) by sight of pinned ears (conditioned cue). The ability to predict the outcome reduces stress in the lives of prey animals. This can work against us. For example horses who shy at needles. Pretty soon they see the vet and are overwhelmed with fear before they even interact with them. On the bright side, horses can easily be re-trained with counter conditioning. If a horse has an innate fear response to something, you can create positive associations using a stimulus they would enjoy rather than fear. An example would be a worming tube; most horses dislike it due to of the awful taste which they associate with the sight of the tube. All of the sudden you cannot get within two feet of them with the tube in your hand. To counter-train this, you can use a clicker and start with the reinforcing of calm behavior around the worming tube. Later, you can progress to reinforcing interest in the object followed by mouthy behavior with the tube. Giving him some honey or sugar water is another method that can produce positive experiences while creating new associations. Consistency is the key. Each horse is unique with different likes, needs, personalities, etc. This is the fun part; one can get creative when exploring what type of stimulus drives your horse, sparking his interests and curiosities. A trainer can also make your cues to be whatever you would like, like constructing a new language that only your horse would understand.

Horses will get accustomed to different aspects of their environment through frequent exposure which results in an eliminated or lowered fear response. This is called habituation, and according to researching veterinarian, Gemma Pearson, this is another aspect of the applied learning theory. An example would be a horse that is desensitized to machinery and vehicles due to stabling near a farm or busy road. Habituation is useful, however there are limits. Progress can 
be a long road. Habituation lays as the foundation for desensitizing training. There are a few different practices for behavior modification based on habituation.

Flooding involves overwhelming a horse with an adverse stimulus until it ceases to react. An example would be locking a horse in a stall with a foreign object in hopes that the horse will eventually get over their fear. Problems due to flooding are elevated stress levels or actually causing more fear. They are unable to act on their flight response and find yet again another situation where the human is the cause of stress.

Stimulus Blending is a method that combines an aversive stimulus with a non-averse one. For example, asking a horse to lower his head by a pull of a rope at the same time you blanket a nervous horse. A stimulus such as lowering is asking the horse to relax into pressure which may help the horse's nerves while the blanket goes on. This method may be effect but still may cause elevated stress. It is typically done with negative reinforcement also known as "pressurerelease".

Approach Conditioning is also known as the "approach-retreat" method. A prey animal naturally runs from things that will chase them. Through approaching then retreating, the horse can quickly habituate to the ability to chase something. They are not too overstimulated at a single time and may gain interest if they find the stimulus to be harmless. The learning is based on negative reinforcement; the removal of the object reduces stress to increase the likelihood of acceptance.

Overshadowing is a method based on the idea that the horse cannot focus on two simultaneous stimuli. When approached with two stimuli, the horse prioritizes which one to focus on while the other stimulus undergoes habituation. Overshadowing commonly acts as a "quick fix" method, especially in situations of immediate attention like with vet or farrier care. 
Such encounters occur under time restraints and are not meant to be training sessions. A common example is the lip twitch. This may just be a distraction. It may get the job done but does not address the actual acceptance of the averse stimulus.

Counter conditioning is the act of using classical conditioning to change a feared stimulus to a positive one. Pearson gives a good example of the use of clippers. A horse that fears clippers can be counter conditioned by receiving a treat once they hear the sound of the clippers (more precision with a clicker). As previously mentioned, classical conditioning requires accurate timing. Clippers need to be turned on before delivering the click or food; if the opposite, they cannot associate the two. The stimulus must come first, then an immediate reward. They are simply making new positive associations. This is intriguing, progressive, and does not break the spirit of the horse. They undergo less stress with counter conditioning while unlocking their curiosity for the previously feared response.

Understanding how horses learn and the types of training involved are only the first steps for understanding what is going on in an equestrian act. However, the effects on equine welfare of various training methods should be studied and addressed in order to promote the future of the equestrian circus. In their 2010 study, "Reinforcement as a Mediator of the Perception of Humans by Horses" Sankey and researchers put this question to the test and measured and compared equine heart rate and emotional state under the two different types of reinforcement. The team of researchers measured the horses' short and long term perception of the human, just after training and five months later. 21 ponies underwent experimentation. They were of mixed breeding made up of 11 mares and 10 geldings from two different riding schools. None of which were ever taught to back up nor had prior introduction to the trainer. The ponies were fitted with heart rate monitors in their training sessions which typically lasted one to three minutes, once a 
day, for five days. Each pony was given three chances, at $10 \mathrm{sec}$ each to respond to the cue "recule!" which is French for "go back!" The negative reinforcement group used an adverse stimulus such as a carrot stick in front of their head and body. By trial one, if the pony did not back, the stick was shook in front of the pony until they stepped back. Right when the pony stepped back, pressure was let off and the pony was led back to its home stall/pasture. The positive reinforcement group was started the same, given the vocal cue, but by the second trial, the experimenter gave the cue and stepped toward the animal with no contact or pressure. When the pony stepped back, following the trainer, a reward of a carrot or pelleted feed was immediately given and the pony was lead back to its home stall/pasture (759).

Not to my surprise, the results showed numerous statistically significant differences. While none of the ponies understood the vocal command on day one, by day five 11 out of 11 ponies understood from the positive reinforcement (PR) group and 7 out of 10 from the negative reinforcement (NR) group. The PR ponies were quicker to back on command than the NR group. 5 out of $10 \mathrm{NR}$ ponies responded by the second trial, and 2 by the third. All 11 PR ponies responded by trial number two. Behaviors during training sessions differed. Most NR ponies side stepped during their training task while none of the PR ponies did. All NR ponies laid their ears back in at least one of the five day sessions when the carrot stick was applied while all of the PR ponies pricked their ears forwards during an average of three out of five sessions. Most NR ponies were reported to have their head raised with some tossing while backing up. Most PR ponies had their heads either neutral or lowered. The NR ponies displayed hollow necks while backing and PR ponies displayed rounded necks. On day one, before the experiment, the groups showed no difference in heart rates. Over the entire training period the mean heart rate was higher in NR ponies than PR ponies. Studies even indicate that on day one, heart rate increased 
at the exact moment of agitation from the stick. There was no heart rate increase in the PR group, not even when the experimenter stepped forward toward the pony or while receiving treats. From day three on, the NR ponies showed increased heart rates before the researcher even gave the vocal cue, predicting the adverse stimulus. Before training, both groups showed similar interest responses to the human. After training, PR ponies were faster to initiate contact with the trainer and spent more time near the trainer, while only two NR ponies came to greet their trainer. After five months, again only 2 NR ponies came to greet the trainer (one being the same pony as in the short term trial) and 10 out of 11 PR ponies greeted their trainer. PR ponies were faster than NP to initiate contact with an unknown person and spent more time near her. These are astonishing results of only five training days consisting of only one to three minute sessions. The use of positive associations also yielded faster and stronger results with better memory recollection, thus becoming a win across the board.

Positive reinforcement produces a win for the horses. It showed no signs of increased heart rate or stress, and a win for humans who formed stronger bonds along with faster training success with quality results. A 2006 study, “Operant Conditioning Programme for White Rhinoceros and Indian or Greater One-Horned Asian Rhinoceros" shows that horses are not the only creature to have greater success with positive reinforcement training. Another study by Sankey and researchers, "Training Experience Induces Lasting Memories of Humans in Horses, Equus Caballus." showed that horses trained with positive reinforcement learnt faster a series of handling and veterinary procedures using such strategies than horses trained without it. Arousal levels need to be significant in order for learning to occur and stress is known to impair attention and learning (Mendl, 1999). Stress may drive the attention from the task itself to the human holding the stick which causes the vocal cue to be associated with the stick rather than the task 
(Shors, 2004, Bisaz et al., 2009) as it did with the NR ponies by day three. And as far as behaviors goes, studies show us that head tossing indicates discomfort (Warren-Smith and McGreevy, 2007; Sondergaard and Halekoh, 2003) as our PR also ponies displayed. Positive reinforcement promoted roundness and self-carriage, encouraging fundamentals of equitation (Warren-Smith and McGreevy, 2007). Hinde's study (1979) shows us that a succession of negative interactions can lead to a negative memory of the partner, hence why the recollection and trainer greeting was much higher in PR ponies.

It is quite clear for horses and for researchers that human presence with positive reinforcements leads to a more positive perception of human and handling procedures (Hausberger et al, 2008). And other studies (DePassille et al., 1996; Munksgaard et al., 1997) show that fear of humans and handling is reduced in the horse when human presence was associated with food rewards. We already knew that horses have good long term memories, but we have underestimated them. Hanggi and Ingersoll's 2009 study showed that horses can recall tasks more than ten years later! Horses can also generalize their daily positive human interactions to unknown humans, thus decreasing stress and increasing equine welfare in a human controlled world (Henry et al., 2005), which may be why PR ponies were all more comfortable approaching strangers.

There are times in which positive reinforcement cannot be the only stimulus applied. Most of the horse industry uses mainly negative reinforcement. Applying pressure from the rider with the use of leg and hand pressure, with the bit and spurs, or perhaps from the liberty trainer using whip pressure to move certain body parts of the horse; however, combining negative reinforcement with positive reinforcement has positive effects on welfare and training. Many equitation trainers insist on the importance of secondary positive reinforcements in 
correspondence with primary ones. Researcher and equestrian Oliveria (1991) would stress for a horseman to have a pocket full of treats when working with a young or green horse. Adding the positive reinforcement adds reassurance to the horse that they are doing what the trainer would like, thus increasing communication, clarity, and welfare to the performing animal.

In his book Gallop to Freedom: Training Horses with Our Six Golden Principles, Frederic Pignon, Cavalia's phenomenal horse trainer and performer, describes his experiences with his no punishment equality training philosophy. He explains that confusion and miscommunication is more abusive, cognitively speaking, than straight forward abuse or neglect. While neither is encouraged as a training method, pure abuse and neglect teaches the horse that the human is unsafe, period. Using ethical training in the ring but still acting controlling and rough in the barn tells the horse you want his trust before you go and turn on them, displaying true predatory tendencies. The same is true for the more common reverse situation; kindness in the barn then rough and controlling riding sessions. Any type of animal training needs consistency. That starts the moment you enter the horses' environment and does not end until you are away from the stable grounds. Ensuring that a performing horse receives consistent, kind, and clear training should be the main goal of any circus, performance, or sport. Let's say that this priority is achieved, the performing horse is receiving clear and ethical training, but how might this still look to a general audience?

Negative reinforcement cues are just that - they are cues, often combined with positive reinforcement, training tools such as whips, bits, and spurs often come with negative connotations from audience members. However, the tool can be taken, wrapped in fancy wording, and can transform perceptions. Past studies have been conducted regarding audience perceptions of various animals in the circus. Roberto Zanola, an Italian researcher, surveyed 
audience attendees at the Acquatico Bellucci Circus in Italy. His questionnaire analyzed audience preferences for circus animals. His results showed that higher preferences for animals in circus correlated with more frequent visits to a circus. A big surprise with the results showed that younger circusgoers with higher education were less sensitive to the animal welfare group claims (3319). This data lays a key solution to misunderstanding of circus animals and circus performances. The higher the education, the more open minded an audience member will be to an animal circus act and the welfare in the ring and behind the scenes. There is an understanding for how horses learn and how to increase horse happiness and welfare in a training program, but what do the experts have to say?

In a 2009 study done in the Netherlands, the Minister of Agriculture commissioned a research a research project to investigate any threats to the welfare of circus animals. Some of the empirical research in the study involved the point of view from "hands on" experts such as performers, trainers, veterinarians, etc. regarding the welfare of animals in their specific context. This study examined the perceptions of four major groups; current trainers and performers, former trainers and performers, veterinarians, and an owner of a shelter working with circus animals. Respondents answered questions regarding quality of animal welfare including training style, housing, exercise, distraction, feed and water supply, and the handling of ill and aged animals. Results of this study showed that other than the topic of how ill and aged animals should be treated, all other aspects of how things should be were fairly similar between the different groups. Every contributor indicated that animal welfare was of high importance to them along with the need for legislation (Viksen, 57). The differences in the results seen in the study were in the levels of welfare that was considered essential to each particular group, creating different levels of normality among the respondents. 
Nijland, Aarts, and Renes results were both quantitative and qualitative. Data of the study showed that when examining current practices in Dutch circuses, results were divergent. Many current trainers and performers agreed that existing situations provided sufficient welfare to the animals, while those outside of the group of current trainers and performers mainly thought that circuses did not meet satisfactory means in the realm of welfare. Every group did agree that circus tend to come across "bad apples" and that these issues or problem makers should be properly addressed and corrected. Overall results were placed on a gradient with descriptions ranging from "The goal of entertaining people does not outweigh the negative welfare of animals in circuses" to "The welfare of animals in circuses is sufficiently warranted: both human and animal enjoy the performance" (526). The results of the various groups did not fit into fixed perceptions on the gradient; however patterns were present within the results.

Data for current trainers and performers rated welfare of circuses to a high degree, and also seemed to be based off of a shared collective tradition of values, norms, interests, and knowledge acquired from a working circus upbringing. Daily life with circus animals and performing for audience created a value or norm that was somewhat based on high welfare in current practices combined with mixed impressions of what performers believe audience member might want to see. "Why wouldn't the animal be in a circus? They don't have a problem with it, they are being taken care of, they get exercise and they like performing." Such narratives come from the notion that audiences seek out circuses to see such performing animals. Current trainers and performers stressed that a shift in welfare standards of keeping and training animals was now present in comparison to the lifestyle and standards present during the reign of former trainers and performers. 
Former trainers and performers were comparable to current trainers and performers when talking about their former circus careers; however it was noted that many quit due to an acquired conviction that animal welfare is insufficient in circus. This group had a much more symbolically diverged narrative from current performers and trainers. This group had more occurrences to stop and defend the left side of the gradient for protecting animal welfare. This group stressed the lack of financial interest in animal welfare. "Survival of circuses, ok, but does that have to be at the expense of animals? I think it shouldn't. And isn't it the case, that when a small family circus owns three lions, that those lions secure the survival of that circus? One day those lions will die and then they have to get new lions and train them and then, well sorry! I say, just think of something else to keep your business going. And that's that" (61). With up to date knowledge of current daily care, this group had a higher desire to update current practices.

Veterinarian results were similar to that of former trainers and performers in that welfare in circuses ranged from sufficient to insufficient. Norms and values for the veterinarian group were much more specific and scientific in descriptive details, especially in the means of health care; feed, water, illness, stress, etc. "Circus are in my opinion better than the wild: animals get older, are vaccinated, de-wormed, there is regulation of disease, food is given, there is no need to hunt, no droughts. Negative sides are the boundaries, but having no boundaries is also stressful and dying in wildlife can be majorly cruel, Of course the traveling stress should be looked into" (66). With knowledge from veterinary practice, those veterinarians that worked solely with circuses were located in the right side of the gradient while vets that worked with welfare and protection groups were located in the left, having values and norms that suited the individual interest. "One's ethical norms obviously depend on your frame of reference. That is of course how we deal with companion animals and livestock. You have to see everything set in our 
current society, in the current time. People with more influence are allowed more. Nobody touches horseries for example (66)."

Lastly, the owner of an animal shelter working with circuses did not share similar stories or standards on the welfare conditions. Landing on the left side of the gradient, the response was positioned on the idea that circuses never did and never will provide sufficient welfare simply due to the nature of circus life. Values and norms for this group were much stricter than those of trainers and performers, even to go as extreme to point that animals should not be captivity at all. "Animal welfare is the recognition that any species or animal is as we are, they have needs that we're obligated to provide. It's their right to have a choice and it's their right to have a good environment in which to live" (67). Their knowledge stemmed from personal experience with entertainment animals in film and photo along with literature on the subject matter. Interests were intently left driven based on the ideology of "doing the right thing".

In order to come to an agreement for welfare standard of circus animal training and lifestyles, open dialogue must be present. Debate will provide insight into similarities and differences among various perceptions into the issue on the table. Experience shapes context for values and norms, and just as this study showed, perception of circus animal welfare were across the board based on the context group. Dutch philosopher Baruch De Spinoza, author of Ethics, published in 1677, was not incorrect when he said, “we don't desire what is good, we judge as good what we desire." We do find consistency among audience members and experts when there is a shared knowledge and higher education on the matter. Creating a standard based on empirical data will at least give the industry something to guide and strive for on the topic of welfare. 
Viksten and researchers of the Swedish University of Agriculture Sciences compared the application of two horse welfare assessment protocols. This comparative study looked at the effectiveness of various protocols that examined different aspects of welfare. Created to be distributed in a timely manner and also examine behaviors, body wellness, compliance with legislation, and risk factors, a standard protocol such as these should be considered from all circuses in order to perform at some sort of universal standard (57).

The success and audience support of Cavalia was due in part from contribution of an open dialogue between audience members and trainers and performers. Offering a "behind the scenes tour" allows audience members to explore the warm up ring and view training sessions. Founder of Cavalia's artistic theme and training methodology, Frederic Pignon, considers his training to be an ethological approach. When we compare the literature and training manuals of Astley and Pignon, methodology looks nearly identical. Though private training sessions can come off as "cruel" for an audience member can have a mind wander into incorrect perspectives, for the mind is designed to fill in the bank from what one knows from previous experience and standards. Cavalia's move to open up and offer an example of behind the scenes training and welfare was an excellent offering to ensure alterations of perceptions. In order to be put on display, one must have nothing to hide. If ethical horse training and care practices are taking place, then the behind the scenes should always be open to answer and curiosities and correct false notions on the welfare of the performing circus horse.

Education and openness is key. Using empirical data, we found the proper form of ethical training for the circus horse. Using education and knowledge, proper training and care practices can be discussed and made priority for the circus horse. Education grants us the proper material from which to set a standard by, while knowledge allows the mission and word to be spread in 
order to ensure an increase in welfare in the circus industry. Just as Phillip Astley wrote his academic horse training manual and also presented his work at Oxford, the spread of knowledge and ideas is the only way to spread information. 


\section{CONCLUSION: THE FUTURE OF THE EQUESTRIAN CIRCUS AND WELFARE OF THE PERFORMING HORSE}

Phillip Astley, father of the modern circus and world renowned horseman, set the tone for the success of the equestrian circus. Stunt rider, horse trainer, riding teacher, and entrepreneur, Astley had the right formula to get his circus off and running with great popularity. Death defying feats of horsemanship were the primary focus of the world's first modern circuses. Amphitheaters and riding halls popped up all over Europe and the United States, all with a primary focus in equestrian acts. Underlying his efforts to create great art, his passion for equitation science was his driving force behind his success. With strict training methodology that promotes kindness, trust, and effectiveness, Astley knew that education and knowledge had an important place in the equestrian circus.

Fast forward to the $19^{\text {th }}$ century and the rise of animal activism put the success of the equestrian circus on the back burner. Aiming at the unfairness to the exotic animals in circus, the effects of the animal activism movement rippled into the equine fraction of the circus. What was once the primary focus of the circus was now dropping popularity to thrill and aerial acts. While horses land on the spectrum of domestication, falling under the category of "animal acts" grouped horses with exotics. However, when we do a comparative analysis of the welfare of the circus horse versus other means of equestrian displays such as rodeos, races, and competition, the circus meets welfare standards. Circus horses have lower physical demands, longer careers, and usually end up in forever homes. Undressing the traditional circus, there is nothing but continuous underlying promotion for equine welfare. The glitter, feathers, and glam come with negative associations from historical exotic animal abuse or pop culture influence of fiction tales of the rough life of circus animals. 
Examining the lifestyle and career of the circus horse surpasses the welfare of other equestrian industries. Circus work can act as a safe haven for horses in a world where "employment" means life or death to a horse. In order for more circuses to be open to accepting equine performers, a revival of the equestrian circus is among us in the form of traditional circus with a new twist. Contemporary hippodramas such as Cavalia, take the same acts that Astley created and reface them with the theme of natural togetherness between horse and human. Following the ticket sales of new emerging eclectic audiences, Cavalia's success can be recognized not by the acts or talent itself, but by the themed façade for the audience. Such spectacles are shedding a positive life on the performing horse and the hippodrama.

Adapt or die, the phrase every industry must go through. Successful performers like Sylvia Zerbini understand this concept, from Ringling to Cavalia, great performer still stand today with their tailed performers by following the new flow of ticket sales and audience preferences. While Cavalia does aim to promote equine welfare, historically speaking, the circus always has, Cavalia simply knows how to sell it to a modern audience. Following Cavala's example can result in the resurrection of many shows such as Ringling and Big Apple Circus. Even if acts are the same, production elements and themes magnetize audiences and after all, those ticket sales pay the food bills of horses and humans alike.

While dressing up the show to meet audience preferences does indeed contribute to the success of a show, improvements to equine welfare in the circus can always be revised and promoted to ensure the truth in the product being advertised and sold. Ethological training ensures ethical horse training with empirical research to support such methodology. Travel, housing, exercise, and other factors contributing to the lifestyle of the circus horse should be maintained to a standard that professionals can agree on. 
Finally, the last part of the formula for ensured success of the hippodrama is to spread knowledge in order to alter current perspectives of the equestrian circus. Education is needed to ensure that welfare quality can continue to rise in the industry, but an open dialogue must be maintained in order to spread new research in the industry. Through embracing Astley's original acts and passion for equitation science, the modern equestrian circus can success in following such traditions but with changing themes to sell to a wide array of modern audiences. The equestrian circus was once a favorite amongst popular live entertainment. Not only will keeping this industry going preserve an ancient art, it will also serve as a great place for horses to work and live out their days.

This study serves as an archival and comparative work, but does not provide any original empirical data. As a theatre studies piece with a rich background in science and equitation studies, future work opportunities can take the form of scientific studies where theory is put into practice. The implications of laying the groundwork in an art study can only launch the success of a future study forward. This piece may not be groundbreaking for the industry; however it can provide information needed for future studies to come. 


\section{REFERENCES}

AAP. “10,000 Wild Horses to be Culled in N.T.” The Australian, 22 May 2013.

Astley, Phillip. Astley's System of Equestrian Education, T.Burnside, 1802.

Baston, Kim. “'New’ Hippodrama, or 'Old' Circus?: Legacy and Innovation in Contemporary Equestrian Performance.” Popular Entertainment Studies, vol. 7, no.1-2, pp.21-28.

Baston, Kim. "Transatlantic Journeys: John Bill Ricketts and the Edinburgh Equestrian Circus." Popular Entertainment Studies, vol. 4, no. 2, 2013, pp.5-28.

Bennie, Angela. “The Circus Honours its Goal of Entertainment.” Australian, 30 December 1987, p. 10.

Berger, John. "Why Look at Animals.” About Looking. New York: Pantheon, 1980.

Bevilacqua, Michael. Beyond the Dream Horse-A Revealing Perspective on Attaining a True Relationship, Equi-Forme, 2010.

Boeckler, Sharon, director. From the Kill Pen. Sila Productions, 2016.

Courchesne, Andre, and Philippe Ravanas. "How to Engage Audiences with Increasingly Eclectic Tastes: The Experience of TOHO, a Montreal Circus Arts Presenter.” International Journal of Arts Management, vol. 18, no. 1, 2015, pp.78-87.

DePassille, AM., Rushen, J., Petherick, JC. “Dairy Calves' Discrimination of People Based on Previous Handling.” Journal of Animal Science, vol.74, 1996, pp.969-974.

Derrida, Jacques. "The Animal that Therefore I Am.” Animal Philosophy: Ethics and Identity. Ed. Matthew Calarco and Peter Atteron. New York: Continuum Publishing, 2004, pp. 113-128. 
"Economic Impact of the United States Horse Industry." American Horse Council, Your Unified Voice in Washington, 2017, http://www.horsecouncil.org/economics/. Accessed 5 February 2018.

Glionna, John. “Auction Sends Wild Horses to Sanctuary - or Slaughter.” Los Angeles Times, 19 June 2013.

Hanggi, EB., Ingersoll, JF. "Long-term Memory for Categories and Concepts in Horses (Equus Caballus)." Animal Cognition, vol,12, no.3, 2009, pp.451-462.

Hausberger, M., Roche, H., Henry, S., Visser, E. “A Review of the Human-Horse Relationship.” Applied Animal Behavior Science, vol.109, 2009, pp.1-24.

Henry, S., Hemery, D., Richard, MA., Hausberger, M. "Human-Mare Relationships and Behavior of Foals Towards Humans." Applied Animal Behavior Science, vol. 93, 2005, pp.341-362.

Holden, MD., Gregory, J., Watkins, V., Radford, L. “Operant Conditioning Programme for White Rhinoceros and Indian or Greater One-Horned Asian Rhinoceros.” International Zoo Year Book, vol. 40, 2006, pp.144-149.

Hrkach, Jack. "Music, Drama, and Horsemanship! Hippodrama in the Circuses of Antebellum New York State." The Mid-Atlantic Almanac: The Journal of the Mid-Atlantic Popular/American Culture Association, vol. 4, no. 1, 1995, pp. 43-53.

Jando, Dominique. “Katja Schumann.”Circopedia. http://www.circopedia.org/Katja_Schumann. Accessed 4 February 2018.

Jando, Dominique. "Short History of the Circus." Circopedia. http://www.circopedia.org/SHORT_HISTORY_OF_THE_CIRCUS\#The_End_of_the_E questrian_Circus. Accessed 4 August 2017. 
“Jenny Vidbel.”Circopedia. http://www.circopedia.org/Jenny_Vidbel. Accessed 5 February 2018.

Kane, Ed. "Predisposed to Injury: Different Sports Carry Different Risks for Horses." Veterinary News DVM 360, 1 December 2014. http://veterinarynews.dvm360.com/predisposedinjury?pageID=2. Accessed 8 March 2018.

Karimi, Faith. "Ringling Bros. Elephants Perform Last Show.” CNN, 2 May 2016. https://www.cnn.com/2016/05/01/us/ringling-bros-elephants-last-show/index.html. Accessed 5 March 2018.

Kormann, Carolyn. “A New Documentary Seeks to Capture the Plight of America's Wild Horses.” The New Yorker, 10 January 2018. https://www.newyorker.com/tech/elements/a-new-documentary-seeks-to-capture-theplight-of-americas-wild-horses. Accessed 9 March 2018.

Kwint, Marius. "The Legitimization of the Circus in Late Georgian England." The Past and Present Society, Oxford, 2002, pp. 72-115.

Ladewig, Jan. "The Role of the Veterinarian in Animal Welfare.” Acta Veterinaria Scandinavica, vol. 50, 2008, pp.1-1.

Laird, Cheryl, and Sandra Oliynyk. ““'Playing with Cavalia's Horses” Practical Horseman, 1 February 2008, pp 34-37.

Lavers, Katie. "Horses in Modern, New, and Contemporary Circus.” Animal Studies Journal, vol. 4, no. 2, 2015, pp.140-172.

Lawler, Dan and L. Leon Geyer. "The Horse Slaughter Conundrum.” Choices: The Magazine of Food, Farm \& Resource Issues, vol. 30, no. 1, 2015, pp.1-6. 
“Long Term Stabling is no Life for a Horse, says Professor." HorseTalk, 13 August 2013. https://www.horsetalk.co.nz/2013/08/13/stabling-no-life-horse-professor/. Accessed 8 March 2018.

McGreevy, Paul, Andrew McLean and Sophie Barrington. "Ethological Challenges for the Working Horse and the Limitation of Ethological Solutions in Training." Equitation Science International, 5 August 2015. https://www.esi-education.com/ethologicalchallenges-for-the-working-horse-and-the-limitations-of-ethological-solutions-intraining/\#. Accessed 9 February 2018.

Mendl, M. "Performing Under Pressure: Stress and Cognition Function.” Applied Animal Behavior Science, vol. 65, 1999, pp.221-244.

Mullan, Dillon. "Hundreds of Racehorses Die at the Track Each Year. Their Deaths may be Preventable." The Washington Post, 13 July 2016. https://www.washingtonpost.com/sports/hundreds-of-racehorses-die-at-the-track-eachyear-their-deaths-may-be-preventable/2016/07/13/1250df9e-3412-11e6-8ff77b6c1998b7a0_story.html?utm_term=.94d2c01ebf46. Accessed 8 March 2018.

Munksgaard, L., DePassille, AM., Rushen, J., Thodberg, K., Jensen, MB. “Discrimination of People by Dairy Cows Based on Handling.” Journal of Dairy Science, vol. 80, 1997, pp.1106-1112.

Nijland, H., Asrts, N., Renes, R. "Frames and Ambivalence in Context: An Analysis of HandsOn Experts Perceptions of the Welfare of Animals in Traveling Circuses in the Netherlands.” Journal of Agriculture and Environmental Ethics, vol.26, 2013, pp.523535.

Oliveria, N. L'art equestre. Ed Crepin Leblond, Paris, 1991. 
Pearson, Gemma. "Practical Application of Equine Learning Theory, Part 1." In Practice, vol. 37, 2015, pp. 251-254.

Pearson, Gemma. "Practical Application of Equine Learning Theory, Part 2." In Practice, vol. 37, 2015, pp.286-292.

Peer, Elizabeth Ann. "Cavalia Horse Show Brings a Circus Atmosphere." Marin Independent Journal, 3 August, 2004. Media NewsGroup Inc., Newsbank Inc., San Rafael, CA.

Pignon, Frederic, Magali Delgado, and David Walser. Gallop to Freedom: Training Horses with the Founding Stars of Cavalia, Trafalgar Square Books, 2009.

Regan, Tom. Empty Cages: Facing the Challenge of Animal Rights, Rowan \& Littlefield Publishers, Lanham, Maryland, 2004.

Regan, Tom. The Case for Animal Rights, Routledge and Kegan Paul, London, 1983.

"Reseau Ovation Inc." Cavalia-Choose Your Tickets. https://www.ovation.qc.ca. Accessed 2 February 2018.

Riemsdijk, Lenka, et al. "Marketing Animal-Friendly Products: Addressing the Consumer Social Dilemma with Reinforcement Positioning Strategies.” Animals, vol. 7, no.98, 2017, pp. $1-20$.

Rosen, Kenneth R. "Retired Big Apple Circus Animals Prepare for Their Second Act." The New York Times, 23 January 2017, A19.

Sankey, C., Richard-Yris, MA., Henry, S., Fureix, C., Nassur, F., Hausberger, M. "Reinforcement as a Mediator of the Perception of Humans by Horses (Equus caballus)." Animal Cognition, vol.13, 2010, pp.753-764. 
Sankey, C., Richard-Yris, MA., Leroy, H., Henry, S., Hausberger, M. “Training Experience Induces Lasting Memories of Humans in Horses, Equus caballus." Animal Behavior, vol.79, 2010, pp.869-875.

Shors, T. “ Learning During Stressful Times.” Learn Memory, vol. 1, 2004, pp.137-144.

Singer, Peter. Animal Liberation: A New Ethics for our Treatment of Animals, Harper Collins, London, 1975.

Spondergaard, E., Halekoh, U. “Young Horses' Reactions to Humans in Relation to Handling and Social Environment.” Applied Animal Behavior Science, vol. 84, 2003, pp.265-280.

Sugarman, Robert. "The New Circus: The Next Generation." Journal of American and Comparative Cultures, vol. 24, no. 3-4, 2002, pp. 438-441.

Sylvia Zerbini and her Amazing Horses. Grand Liberte, 2017, http://sylviazerbini.com/. Accessed 5 February 2018.

Tait, Peta, and Rosemary Farrell. "Protests and Circus Geographies: Exotic Animals with Edgley's in Australia." Journal of Australian Studies, vol. 34, no. 2, 2010, pp. 225-239. Van Gelder, Lawrence. "Circus Review; Three Ring Thrills Distilled into One." The New York Times, 2 December 2000.

Viksen, S., Visser, E., Blokhuis, H. “A Comparative Study of the Application of Two Horse Welfare Assessment Protocols.” ACTA Agriculture Scandinavia,vol.66, no.1, 2016, pp.56-66.

Warren-Smith, AK., McGreevy, PD. "The Use of Blending Positive and Negative Reinforcement in Shaping the Halt Response of Horses (Equus Caballus)." Animal Welfare, vol.15, 2007, pp.481-488. 
We Never Gave Up: PETA's Triumph Over Ringling Bros. PETA, 2018, http://www.peta.org/features/ringling/. Accessed 5 June 2018.

Wheatley, Dennis. The Time Has Come: Officer and Temporary Gentleman. Vol.2. London: Hutchinson-Random House, 1978.

Williams, Laura. "Annual Cost of Owning a Horse and 4 Alternatives to Buying." Money Crashers. https://www.moneycrashers.com/cost-owning-horse-alternatives-buying/. Accessed 9 March 2018.

Xenophon, Circa 350 BC. “On Horsemanship, by Xenophon.” In: The Project Gutenberg EBook. Translated by H.G. Dakyns, 1998. Available at: http://www.gutenberg.org/files/31957/31956-h/31957/-h.htm. Accessed 12 December 2016.

Zanola, Roberto. “Who Likes Circus Animals?” Access Economics, vol.30, no.4, 2008, pp.33153320. 